\title{
Colour Doppler study of uterine artery between 10-14 weeks of gestation as a predictor of intra-uterine growth restriction and preeclampsia
}

\author{
Nupur Mittal*, Pragyashree, Priya Sharma, Soniya Vishwakarma
}

Department of Obstetrics and Gynaecology, UP Rural Institute of Medical Sciences and Research, Saifai, UP, India

Received: 21 June 2016

Accepted: 09 July 2016

*Correspondence:

Dr. Nupur Mittal,

E-mail: forever_nupur246@yahoo.co.in

Copyright: (c) the author(s), publisher and licensee Medip Academy. This is an open-access article distributed under the terms of the Creative Commons Attribution Non-Commercial License, which permits unrestricted non-commercial use, distribution, and reproduction in any medium, provided the original work is properly cited.

\section{ABSTRACT}

Background: Successful pregnancy is a result of countless ongoing interactions between the placental and the maternal immune and cardiovascular systems. Pre-eclampsia and intrauterine growth restriction (IUGR) remains important causes of maternal and neonatal morbidity and mortality. These conditions arise from placental insufficiency which can be seen as alterations in waveforms in the uterine artery (UtA) in early pregnancy. We investigated the predictive accuracy of UtA Doppler indices for both conditions in the first trimester early enough to provide a window for preventive interventions.

Methods: It was a prospective cohort study. (UtA) Doppler was carried out at 11-14 weeks in 100 singleton pregnancies attending for routine care. The right and left UtA were identified and velocity waveforms were obtained. Mean pulsatility index (PI), mean resistance index (RI) and diastolic notch were noted. Results were tabulated and analyzed.

Results: $18 \%$ developed Preeclampsia and 16\% developed IUGR. The first trimester UtA mean RI and mean PI were significantly higher in patients who are destined to develop Preeclampsia and IUGR. No significant relationship was found between IUGR, Preeclampsia and diatolic notch. Mean RI is a better predictor of IUGR and Pre-eclampsia compared to Mean PI. Using receiver operating characteristics (ROC) curve, the best cut-off of mean RI to detect the Pre-eclampsia and IUGR is 0.68 .

Conclusions: UtA Doppler at 11-14 weeks of gestation identifies a high proportion of women who will develop severe pre-eclampsia, and/or IUGR.

Keywords: Preeclampsia, IUGR, Uterine artery Doppler, Resistance index, Pulsatility index

\section{INTRODUCTION}

Pre-eclampsia and Intra uterine growth restriction (IUGR) remain important causes of maternal and neonatal complications and death. ${ }^{1-3}$ Although the incidence of Pre-eclampsia in the general obstetric population is only $5 \%-10 \%$, there is a potential for serious adverse outcomes. ${ }^{1,3,4,5}$ These conditions results from abnormal placenta formation involving abnormal trophoblast invasion of spiral arteries and a reduction in vascular resistance in the uteroplacental circulation. ${ }^{6-8}$ Early-onset pre-eclampsia is associated with a 20 -fold higher rate of maternal mortality than is late-onset disease and is one of the key contributors to early fetal growth restriction. Infants are often delivered preterm, need prolonged intensive care and develop complications, including lifelong disability like diabetes, hypertension. Symptoms generally manifest in second to third trimester of pregnancy, but their underlying pathology begins in the first trimester. ${ }^{6,9-11}$ Accurate prediction is therefore paramount to provide appropriate antenatal surveillance and therapy to improve perinatal outcomes. 
Uterine artery (UtA) Doppler velocimetry has revolutionized the investigation of the developing placental vasculature showing that impedance to flow in the uterine arteries decreases with the gestational age in normal pregnancy. ${ }^{12}$ But this impedance to flow is increased in established pre-eclampsia and IUGR even before the clinical signs of the disease are seen. ${ }^{13,14}$

Hence, this study is designed to focus on the employment of Doppler ultrasound in the first trimester which may provide an excellent opportunity to screen for these pregnancy complications at an early stage, when intervention might be possible for the successful pregnancy outcome.

The aim of this study is to investigate the role of colour Doppler in first trimester of pregnancy in predicting Preeclampsia and Intra uterine growth restriction.

\section{METHODS}

This was prospective cohort study, conducted on 100 women in the age group 19-33 years with singleton pregnancy between 10-14 weeks of gestation coming for routine antenatal check-up and was followed till delivery.

\section{Inclusion criteria}

- Singleton pregnancy.

- Gestational age between 10-14 weeks.

- Accurate dating using last menstrual period or ultrasound examination before, in weeks.

\section{Exclusion criteria}

- Carrying a fetus with sonologically detected congenital anomaly.

- Women with any systemic illness like chronic hypertension, renal disease, and diabetes mellitus.

- Multiple pregnancy.

- Those with a known congenital uterine malformation detected in the previous scan reports

After obtaining informed consent, the patient details were recorded. Pregnancy dating was done from the LMP and confirmed by ultrasonography measurements of CRL. General examination findings and vitals were noted. Patients were subjected to Doppler ultrasound examination between 10-14 weeks. Both the uterine arteries were identified with colour Doppler at the point at which they appeared to cross the external iliac artery. The resistance index (RI), pulsatility index (PI) and presence or absence of diastolic notch were assessed in both the uterine arteries. All the patients were followed routinely when their BP was monitored and the presence of urine albumin was noted. Only women with blood pressure $\geq 140 / 90$ measured on two occasions after 20 weeks of pregnancy and with proteinuria of $\geq 1+$ by dipstick or with any sign of disease severity (E.g.;
HELLP Syndrome, Eclampsia, pulmonary edema, and cardiac failure) were considered to be pre-eclamptic. Development of IUGR was detected clinically and also from the interval growth rate and from ultrasound. IUGR was identified when there was no adequate interval growth detected clinically and by the ultrasonography; when the fetal weight was less than $10^{\text {th }}$ percentile for that gestational age. Fetal parameters considered at delivery were the gestational age at delivery, mode of delivery, birth weight, APGAR, fetal outcome, NICU admission and ventilatory support. The gathered data was entered in Microsoft Excel and appropriate Statistical Analysis done using SPSS software (version 17). Continuous variables were presented as mean \pm SD. Normally distributed continuous variables were compared using Student t-test. A receiver operating characteristics (ROC) analysis was calculated to determine optimal cut-off value for Mean RI and Mean PI to predict Pre-eclampsia and IUGR. For all statistical tests, $\mathrm{p}$ value less than 0.05 was taken to be significant.

\section{RESULTS}

Table 1: Age distribution of study group.

\begin{tabular}{|lll|}
\hline Age in years & Frequency & Percentage \\
\hline $20-24$ & 12 & 12.0 \\
\hline $25-29$ & 72 & 72.0 \\
\hline $30-34$ & 16 & 16.0 \\
\hline Total & 100 & 100 \\
\hline
\end{tabular}

Table 2: Gravity distribution of study group.

\begin{tabular}{|lll|}
\hline Gravida & Frequency & Percent \\
\hline G1 & 60 & 60 \\
\hline G2 & 26 & 26 \\
\hline G3 & 10 & 10 \\
\hline G4 & 4 & 4 \\
\hline Total & 100 & 100 \\
\hline
\end{tabular}

Table 3: Mean RI and mean PI values $(n=100)$.

\begin{tabular}{|l|l|}
\hline Uterine artery Doppler indices & Mean \\
\hline Rt UtA RI & 0.6546 \\
\hline Lt UtA RI & 0.6558 \\
\hline Mean RI (Rt and Lt) & 0.6534 \\
\hline Rt UtA PI & 1.5234 \\
\hline Lt UtA PI & 1.4874 \\
\hline Mean PI & 1.5052 \\
\hline
\end{tabular}

Table 4: Presence of diastolic notch in study group.

\begin{tabular}{|c|c|c|}
\hline Diastolic notch & Frequency & Percentage \\
\hline $\begin{array}{l}\text { Present in both (RT and } \\
\mathrm{LT} \text { ) }\end{array}$ & 46 & $46 \%$ \\
\hline Present in one & 30 & $30 \%$ \\
\hline Absent in both & 24 & $24 \%$ \\
\hline Total & 100 & $100 \%$ \\
\hline
\end{tabular}


In this study, 100 women, representative of the local pregnant population were recruited with a $100 \%$ followup rate. In our study 2 patients developed Eclampsia at 28 weeks and 2 patients developed severe Preeclampsia and IUGR at 31 weeks. LSCS was done in all the cases with poor fetal outcome. Out of 100 cases taken, 18 (18\%) developed Pre-eclampsia. Out of which 6 were early Preeclampsia requiring delivery before 34 weeks. IUGR developed in 16 cases $(16 \%)$ in our study. In our study maternal age ranged from 20-32 yrs with a mean of 27.26 (Table 1).

Table 5: Comparison of UtA Doppler indices between IUGR and normal babies at birth and patients with and without preeclampsia.

\begin{tabular}{|lcccc|c|}
\hline IUGR at birth & N & Mean & $\begin{array}{l}\text { Std. } \\
\text { deviation }\end{array}$ & P value \\
\hline Mean & Present & 16 & 0.7413 & 0.08543 & 0.001 \\
RI & Absent & 84 & 0.6367 & 0.07904 & \\
\hline Mean & Present & 16 & 1.8100 & 0.60651 & \multirow{2}{*}{0.020} \\
PI & Absent & 84 & 1.4471 & 0.34071 & \\
\hline PE at birth & & & & \\
\hline Mean & Present & 18 & 0.7400 & 0.08000 & \multirow{2}{*}{0.001} \\
RI & Absent & 82 & 0.6344 & 0.07861 & \\
\hline Mean & Present & 18 & 1.8611 & 0.49652 & \multirow{2}{*}{0.003} \\
PI & Absent & 82 & 1.4271 & 0.34845 & \\
\hline
\end{tabular}

Table 6: Association of diastolic notch and IUGR and pre-eclampsia cases.

\begin{tabular}{|c|c|c|c|c|c|}
\hline & Notch & $\begin{array}{l}\text { Present } \\
\text { in both }\end{array}$ & $\begin{array}{l}\text { Present } \\
\text { in one }\end{array}$ & $\begin{array}{l}\text { Absent } \\
\text { in both }\end{array}$ & $\begin{array}{l}\mathbf{P} \\
\text { value }\end{array}$ \\
\hline \multirow{2}{*}{ IUGR } & Present & $\begin{array}{l}8 \\
17.4 \%\end{array}$ & $\begin{array}{l}2 \\
6.7 \%\end{array}$ & $\begin{array}{l}6 \\
25 \%\end{array}$ & \multirow{2}{*}{0.42} \\
\hline & Absent & $\begin{array}{l}38 \\
82.6 \%\end{array}$ & $\begin{array}{l}28 \\
93.3 \%\end{array}$ & $\begin{array}{l}18 \\
75 \%\end{array}$ & \\
\hline \multirow{2}{*}{$\begin{array}{l}\text { Pre- } \\
\text { eclampsia }\end{array}$} & Present & $\begin{array}{l}8 \\
17.4 \%\end{array}$ & $\begin{array}{l}6 \\
20 \%\end{array}$ & $\begin{array}{l}4 \\
16.7 \%\end{array}$ & \multirow{2}{*}{0.97} \\
\hline & Absent & $\begin{array}{l}38 \\
82.6 \%\end{array}$ & $\begin{array}{l}24 \\
80 \%\end{array}$ & $\begin{array}{l}20 \\
83.3 \%\end{array}$ & \\
\hline
\end{tabular}

Maximum number of women was between 25-29 years of age. Table 2 shows gravid wise distribution of the study group. In the present study, out of 100 subjects, maximum number of patients was primigravida $(60 \%)$. Mean RI and Mean PI values and presence or absence of diastolic notch are shown in table 3 and 4.

Table 5 and 6 shows that there is significant difference in mean RI and mean PI values between the patients with IUGR and normal birth babies and between preeclamptic and normotensive patients ( $\mathrm{p}$ value $<0.05$ ). Occurrence of IUGR and preeclampsia does not have any correlation with presence or absence of diastolic notch as shown in table 5 ( $\mathrm{p}$ value $>0.05$ ). Pre-eclampsia is significantly associated with IUGR at birth as shown in table 7.12 out of 100 patients developed both Preeclampsia and IUGR. $66.7 \%$ patients with Preeclampsia and $62.5 \%$ patients with IUGR developed oligohydramnios representing a statistically significant association between them as shown in Table 8.

Table 7: Association between pre-eclampsia and IUGR at birth.

\begin{tabular}{|lllll|}
\hline \multicolumn{1}{|c|}{} & & \multicolumn{2}{c}{ Preeclampsia } & \\
& & Present & Absent & P value \\
\hline IUGR & Present & 12 & 4 & \multirow{2}{*}{$<0.001$} \\
\hline & Absent & 6 & 78 & \\
\hline
\end{tabular}

There is a significant relationship between gestational age at delivery, APGAR score and, IUGR and Pre-eclampsia (Table 9). Preeclamptic patients deliver significantly SGA babies as compared to normotensive patients.(table 10, mean wt $1.7 \mathrm{~kg}$ ). $75 \%$ of patients with IUGR underwent Cesarean section whereas $23.8 \%$ without IUGR had cesarean section $(\mathrm{p}<0.05$; which was statistically significant). Vaginal delivery was performed in $25 \%$ cases of IUGR. $77.8 \%$ of the Pre-eclamptic women underwent cesarean section and only $22.2 \%$ of them had vaginal delivery. $22 \%$ of non-pre-eclamptic women had cesarean section (Table 11).

Mean RI is a better predictor of IUGR and Pre-eclampsia compared to Mean PI since the area under the curve is higher for mean RI (Figure 1 and 2). Using ROC curve, the best cut-off of mean RI to detect the Pre-eclampsia is 0.68 with $78 \%$ sensitivity and $73 \%$ specificity. The best cut off of mean RI to detect IUGR is 0.68 with $75 \%$ sensitivity and $71 \%$ specificity.

\section{DISCUSSION}

The fetal growth and ultimate pregnancy outcome depends to a large extent on continuous flow of oxygen and nutrients from mother to the fetus. The steady supply to fetus occurs by continuous adjustments of uteroplacental and fetoplacental circulation throughout pregnancy.

Our study was mainly centred on using Doppler technique, demonstrating a lower UtA RI and PI in normal outcome pregnancies than in complicated cases, suggesting that a lack of a normal uteroplacental circulation at this early stage of pregnancy may partly predict the later development of some of the pregnancy complications. The period between 10-14 weeks was chosen to perform the uterine artery Doppler because a routine scan for nuchal translucency and early anatomical assessment was scheduled at this time of gestation.

Maternal age ranged from 20-32 yrs with a mean of 27.26 in our study and was 31.3 in the study conducted by Martin et al. ${ }^{16}$

The mean uterine artery RI values changed between 11 and 14 weeks' gestation $(\mathrm{r}=-0.086, \mathrm{P}<0.00001$; mean $\mathrm{RI}=0.872-0.002 \times$ gestation $($ days $))$ with the RI decreasing by 0.002 each day. For the purpose of study, 
the uterine artery indices were considered to be unchanged over this gestational age window, as the magnitude of change was smaller than the accepted observer variability of first-trimester uterine artery Doppler imaging.

In our study we found that Mean RI and Mean PI were higher in patients developing IUGR and Pre-eclampsia ( $p$ value <0.05). These findings are consistent with the studies conducted by Gomez et al who demonstrated a lower impedance in the uterine artery of normal outcome pregnancies than in complicated cases, Martin et al also found high RI index in patients developing IUGR and pre-eclampsia. $^{15,16}$

Table 8: Distribution of oligohydramnios in IUGR and pre-eclampsia cases.

\begin{tabular}{|c|c|c|c|c|c|}
\hline \multirow{2}{*}{ Oligohydramnios (cm) } & \multicolumn{2}{|c|}{ Pre-eclampsia } & \multicolumn{2}{|l|}{ IUGR } & \multirow{2}{*}{ P value } \\
\hline & Present & Absent & Present & Absent & \\
\hline \multirow{2}{*}{ Present AFI $<8$} & 12 & 2 & 10 & 4 & \multirow{2}{*}{$<0.001$} \\
\hline & $66.7 \%$ & $2.4 \%$ & $62.5 \%$ & $4.8 \%$ & \\
\hline \multirow{2}{*}{ Absent AFI $>8$} & 6 & 80 & 6 & 80 & \multirow{2}{*}{$<0.001$} \\
\hline & $33.3 \%$ & $97.6 \%$ & $37.5 \%$ & $95.2 \%$ & \\
\hline
\end{tabular}

Table 9: Fetal parameters at delivery and IUGR and pre-eclampsia.

\begin{tabular}{|lllllll|}
\hline \multirow{3}{*}{ IUGR } & & N & Mean GA (weeks) & P value & Mean APGAR score & P value \\
& Present & 16 & 34.5750 & $<0.001$ & 5.6250 & $<0.001$ \\
\cline { 2 - 7 } & Absent & 84 & 38.5167 & $<.2143$ & $<0.001$ \\
\hline \multirow{2}{*}{ Pre-eclampsia } & Present & 18 & 34.6889 & $<0.001$ & 5.7778 & 7.2195 \\
\cline { 2 - 7 } & Absent & 82 & 38.5878 & & 75 \\
\hline
\end{tabular}

Table 10: Mean birth weight in pre-eclampsia cases.

\begin{tabular}{|lllll|l|} 
& & & \multicolumn{1}{c|}{$\begin{array}{l}\text { Mean } \\
\text { weight } \\
\text { (kg) }\end{array}$} & $\begin{array}{l}\text { Std. } \\
\text { deviation }\end{array}$ & $\begin{array}{l}\text { P } \\
\text { value }\end{array}$ \\
\cline { 1 - 5 } $\begin{array}{l}\text { Pre- } \\
\text { eclampsia }\end{array}$ & Present & 18 & 1.7249 & 0.70432 & $<0.001$ \\
\cline { 2 - 5 } & Absent & 82 & 2.8712 & 0.20953 & \\
\hline
\end{tabular}

Table 11: Mode of delivery in the study group.

\begin{tabular}{|c|c|c|c|c|c|}
\hline & & $\mathbf{N}$ & LSCS & $\begin{array}{l}\text { Vaginal } \\
\text { delivery }\end{array}$ & $\begin{array}{l}\mathbf{P} \\
\text { value }\end{array}$ \\
\hline \multirow{2}{*}{ IUGR } & Present & 16 & 12 & 4 & \multirow{2}{*}{0.004} \\
\hline & Absent & 84 & 20 & 84 & \\
\hline \multirow{2}{*}{$\begin{array}{l}\text { Pre- } \\
\text { eclampsia }\end{array}$} & Present & 18 & 14 & 4 & \multirow{2}{*}{0.001} \\
\hline & Absent & 82 & 18 & 64 & \\
\hline
\end{tabular}

Odibo AO et al found that uterine artery $\mathrm{PI}$ is a reasonable, individual predictor of women at risk to develop pre-eclampsia. ${ }^{17}$ Melchiorre $\mathrm{K}$ et al also found that the first-trimester uterine artery mean RI was significantly higher in women destined to deliver small for gestational age neonates than in women with normal pregnancies (median uterine artery RI, 0.74 vs. $0.70, \mathrm{P}$ $<0.001) .{ }^{18}$ In the study conducted by Fratelli $\mathrm{N}$ et al, among 76 high risk women, 30 (39\%) had abnormal uterine Doppler which was significantly related to higher incidence of preeclampsia ( $17 \%$ vs. $0 \%$; $\mathrm{p}=0.0041)$, fetal growth restriction $(27 \%$ vs. $0 \% ; \mathrm{p}=0.0002)$, intrauterine death , and iatrogenic preterm delivery. ${ }^{19}$

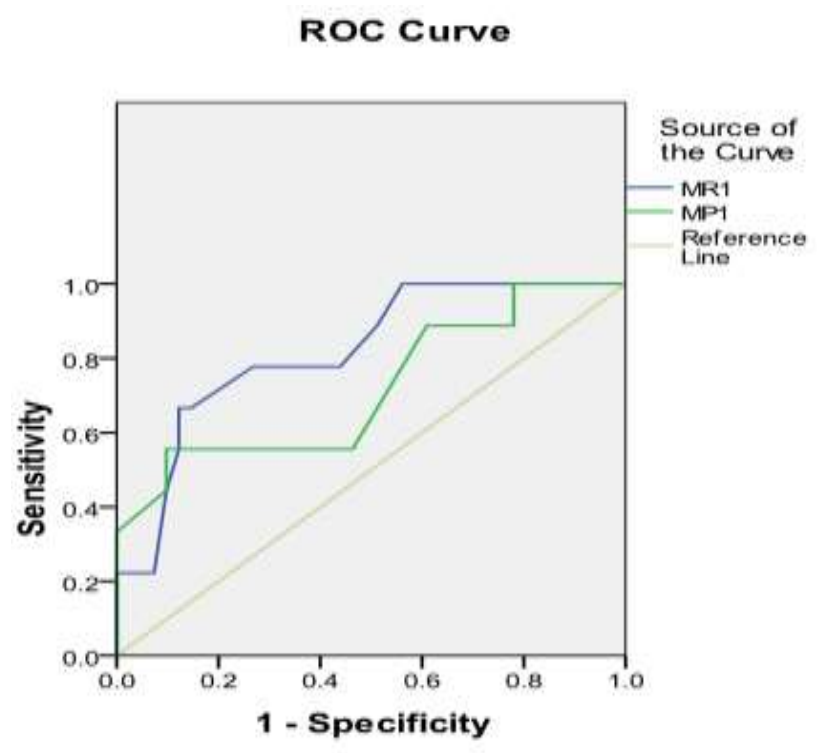

Diagonal segments are produced by ties.

Figure 1: ROC Curve for predicting pre-eclampsia. 


\section{ROC Curve}

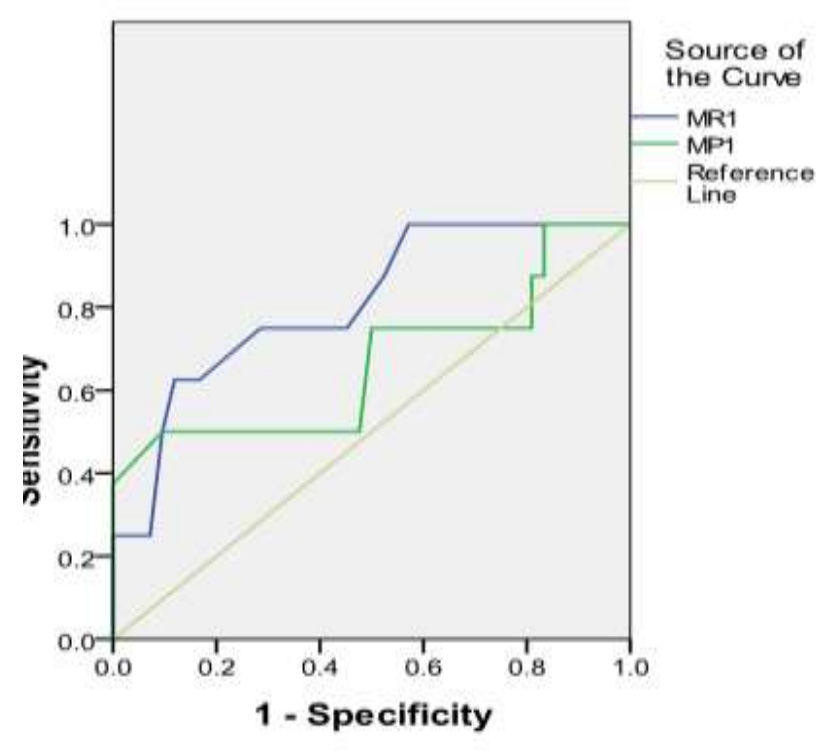

Diagonal segments are produced by ties.

Figure 2: ROC curve for predicting IUGR.

In our study, 16 cases $(16 \%)$ had Mean PI $\geq 2.00\left(90^{\text {th }}\right.$ centile) and this group contained 8 cases $(36.4 \%)$ of those that developed IUGR and Pre-eclampsia similar to the study conducted by Schuchter $\mathrm{K}$ et al in which uterine artery PI was $\geq 90$ th centile in $38(10 \%)$ pregnancies and this group contained nine $(25 \%)$ of those that developed complications. $^{20}$

Mean UtA PI was significantly higher ( $p$ value $<0.05$ ) in Pre-eclamptic cases that required delivery before 34 weeks thus, much better at identifying the more severe and clinically most relevant cases of Pre-eclampsia. Papaqeorqhiou AT et al reviewed the previous studies which showed that for a false positive rate of 5\%, firsttrimester uterine artery Doppler studies will detect 50$65 \%$ of women who will develop severe preeclampsia.

In this study, Receiver-operating characteristics (ROC) curve was used to find out the mean RI cut-off which was 0.68. Based on this cut-off, it was found that with a sensitivity of $77.8 \%$, it could identify $38.9 \%$ of the cases of pre-eclampsia at a false positive rate of $26.8 \%$. Similarly with a sensitivity of $75 \%$, the test could identify $33.3 \%$ of the cases of IUGR at a false positive rate of $28.6 \%$., Mean RI at $75^{\text {th }}$ centile was 0.71 and at $95^{\text {th }}$ centile it was 0.82 . At $75^{\text {th }}$ centile the sensitivity for detecting IUGR and Pre-eclampsia was $62.5 \%$ and $66.7 \%$ with a specificity of $83.3 \%$ and $85.4 \%$ respectively consistent with the findings of Dugoff et al. ${ }^{21}$ In his study Mean RI cut-off at 75 th centile $(0.731)$ and at 95 th centile (0.81). Accordingly at the 75 th percentile, the sensitivity for detecting pre-eclampsia and IUGR was $72.3 \%$ and $66.7 \%$ with a specificity of $84 \%$ and $75 \%$ respectively.
In our study all the patients with Mean RI $>95^{\text {th }}$ centile (0.82) developed IUGR and Pre-eclampsia showing $100 \%$ specificity with $22.2 \%$ sensitivity for Preeclampsia and $25 \%$ for IUGR. This may be because of small sample size.

It has been proved beyond doubt, in the previous studies and in the present study, that pre-eclampsia is significantly associated with IUGR. The sensitivity in the present study of finding IUGR in patients with preeclampsia was $66.7 \%$ with a Positive predictive value (PPV) of $75 \%$. This proves that both these entities: preeclampsia and IUGR, stem from one common pathology which has been known to be early defective placentation.

Mean RI and Mean PI was significantly higher in patients requiring Cesarean section as compared to normal delivered patients suggesting that when Doppler flow indices were abnormal, incidence of fetal distress was more while with normal Doppler, Cesarean section was done mainly for other reasons like CPD, NPOL etc. APGAR score, mean birth weight, was significantly low in patients having raised first trimester uterine Doppler indices. $18 \%$ of the babies received NICU care due to the complications of Prematurity, respiratory distress and IUGR.

The persistence of the notch, with an increased RI and increased PI indicate heightened vascular resistance serving as predictors of pre-eclampsia and adverse fetal outcome. There is a lot of controversy regarding the timing of the disappearance of the notch. The most prevailing opinion is that the notch disappears only in the interval between $19^{\text {th }}$ and $21 \mathrm{st}$ gestational week corresponding to the 2 nd wave of trophoblastic invasion.

The presence or absence of bilateral or unilateral diastolic notch in this study was not found to be statistically significant which is consistent with the study by Martin et al, Dugoff et al. ${ }^{16,21}$

Yet few other studies of J.M. Martinez et al, Carbillon et al, Melchiorre $\mathrm{K}$ et al found that compared with the normal pregnancies, complicated pregnancies had significantly higher persistence of a bilateral notch. ${ }^{22,23}$

The presence of bilateral notches in the first-trimester uterine artery waveform was a relatively poor predictor of pre-eclampsia because of the high prevalence of this finding in normal pregnancies concluding that early bilateral notching alone is unlikely to be useful in screening for pregnancy complications.

Present study, therefore, suggests that Doppler velocimetry in first trimester is a useful investigation in predicting some of the pregnancy complications developing at later gestation. Measures can then be taken to decrease their incidence. Patients developing complications at an early gestation require more intensive 
surveillance and early delivery in some cases may be the only option.

Genital tuberculosis frequently causes infertility and secondary amenorrhea. In a country like India where tuberculosis is endemic a clinician should have a high degree of suspicion when evaluating cases of infertility and secondary amenorrhea.

\section{CONCLUSION}

First trimester UtA RI can be used as a good predictor for pre-eclampsia and IUGR. Pre- eclampsia is significantly associated with IUGR in the low risk population. Lower uterine artery Doppler indices were found in normal pregnancies and patients with raised Doppler indices had more chance of indicated preterm deliveries, oligohydramnios, low birth weight babies, caesarean section, and fetal compromise when compared with those of low Doppler indices. Raised Doppler indices in first trimester is associated with the development of preterm, rather than term, pre-eclampsia and provide supportive evidence for the hypothesis that these disorders may have different etiologies, preterm condition is associated with defective invasion of the spiral arteries, whereas the spiral artery defect plays a much smaller role, if at all, in the cases nearer term.

We, therefore, conclude that Doppler ultrasonography is the best non-invasive investigation to assess changes in uteroplacental hemodynamics. However, a sequential ultrasound Doppler analysis in the second trimester would have further increased the sensitivity of the test and decreased the false positive rate.

\section{AKNOWLEDGEMENTS}

Authors would like to thanks to my respected teachers, all my senior and junior colleagues and nursing staff, who stood by me and supported me at every stage of this study. My deepest gratitude to my husband Dr. Jay, who has been the primary guiding force and a great source of inspiration. With at most sincerity I thank all my patients.

Funding: No funding sources Conflict of interest: None declared

Ethical approval: The study was approved by the Institutional Ethics Committee

\section{REFERENCES}

1. Sibai B, Dekker G, Kupferminc M. Pre-eclampsia. Lancet. 2005;365:785-99.

2. Khan KS, Wojdyla D, Say L, Gulmezoqlu AM, Van Look PF. WHO analysis of causes of maternal death: a systematic review. Lancet. 2006;367:1066-74.

3. Walker JJ. Pre-eclampsia. Lancet. 2000;356:1260-5.

4. Wen SW, Huang L, Liston R, Heaman M, Baskett T, Rusen ID, et al.; Maternal Health Study Group, Canadian Perinatal Surveillance System. Severe maternal morbidity in Canada, 1991-2001. CMAJ. 2005;173:759-64.

5. Roberts JM, Cooper DW. Pathogenesis and genetics of pre-eclampsia. Lancet. 2001;357:53-6.

6. Khong TY, De Wolf F, Robertson WB, Brosens I. Inadequate maternal vascular response to placentation in pregnancies complicated by preeclampsia and by small-for-gestational age infants. Br J Obstet Gynaecol. 1986;93:1049-59.

7. Pijnenborg R, Anthony J, Davey DA, Rees A, Tiltman A, Vercruysse L, et al. Placental bed spiral arteries in the hypertensive disorders of pregnancy. Br J Obstet Gynaecol. 1991;98:648-55.

8. Shanklin DR, Sibai BM. Ultrastructural aspects of pre-eclampsia I: Placental bed and boundary vessels. Am J Obstet Gynecol. 1989;161:735-41.

9. Pijnenborg R, Bland JM, Robertson WB, Brosens I. Uteroplacental arterial changes related to interstitial trophoblast migration in early human pregnancy. Placenta. 1983;4:397-413.

10. Kam EPY, Gardner L, Loke YW, King A. The role of trophoblast in the physiological change in decidual spiral arteries. Hum Reprod. 1999;14:21318.

11. Kaufmann P, Black S, Huppertz B. Endovascular trophoblast invasion: implications for the pathogenesis of intrauterine growth retardation and preeclampsia. Biol Reprod. 2003;69:1-7.

12. Campbell S, Griffin DR, Pearce JM, j DiazRecasens TE cohen-Overbeek, Wilson K, et al. New Doppler technique for assessing uteroplacental blood flow. Lancet. 1983;26:675-7.

13. Trudinger BJ, Giles WB, Cook CM. Uteroplacental blood flow velocity - time waveforms in normal and complicated pregnancy. Br J Obstet and Gynecol. 1985;92:39-45.

14. Ducey J. Complication of Hypertension in pregnancy based on Doppler Velocimetry. Am. J Obstet Gynecol. 1987; 157:680-5.

15. Gomez O. Uterine artery Doppler at 11-14 weeks of gestation to screen for hypertensive disorders and associated complications in an unselected population. Human Reproduction. 2006;21(5):1295-8.

16. Martin AM, Bindra R, Curcio P, Cicero S, Nicolaides KH. Screening for pre-eclampsia and fetal growth restriction by uterine artery Doppler at 11-14 weeks of gestation. Ultrasound Obstet Gynecol. 2001;18:583-6.

17. Odibo AO, Zhong Y, Goetzinger KR, Odibo L, Bick JL, Bower CR, et al. First-trimester placental protein 13, PAPP-A, uterine artery Doppler and maternal characteristics in the prediction of pre-eclampsia. 2011;32(8):598-602.

18. Melchiorre K, Leslie K, Prefumo F, Bhide A, Thilaganathan B. First-trimester uterine artery Doppler indices in the prediction of small-forgestational age pregnancy and intrauterine growth restriction. Ultrasound Obstet Gynecol. 2009;33:5249. 
19. Fratelli N, Rampello S, Guala M, Platto C, Frusca T. Transabdominal uterine artery Doppler between 11 and 14 weeks of gestation for the prediction of outcome in high-risk pregnancies. The Journal of Maternal-Fetal and Neonatal Medicine. 2008;21(6):403-6.

20. Schuchter K, Metzenbauer M, Hafner E, Philipp K. Uterine artery Doppler and placental volume in the first trimester in the prediction of pregnancy complications. Ultrasound Obstet Gynecol. 2001;18:590-2.

21. Dugoff L, Lynch AM, Cioffi-Ragan D, Hobbins JC, Schultz LK, Malone FD, et al. First Trimester Uterine artery Doppler Abnormalities predict subsequent intrauterine growth restriction. American Journal of Obstetrics and Gynecology. 2005;193:1208-12.
22. Carbillon L, Uzan M, Largilliere C. Prospective evaluation of uterine artery flow velocity waveforms at 12-14 and 22-24 weeks of gestation in relation to pregnancy outcome and birth weight. Fetal Diagn Ther. 2004;19:381-4.

23. Melchiorre K, Wormald B, Leslie K, Bhide A, Thilaganathan B. First-trimester uterine artery Doppler indices in term and preterm pre-eclampsia. Ultrasound Obstet Gynecol. 2008;32:133-7.

Cite this article as: Mittal N, Pragyashree, Sharma $\mathrm{P}$, Vishwakarma S. Colour Doppler study of uterine artery between 10-14 weeks of gestation as a predictor of intra-uterine growth restriction and preeclampsia. Int J Reprod Contracept Obstet Gynecol 2016;5:2784-90. 